oestrogens in low doses, or orchidectomy, appears still to be the best treatment. ${ }^{7}$ According to a recent report by a research group the average patient with prostatic cancer derives no benefit from immediate treatment with stilboestrol or by orchidectromy unless the cancer is causing serious symptoms. ${ }^{7}$ The excess mortality associated with oestrogen therapy, even when the dose is restricted to $5 \mathrm{mg}$ daily by mouth, shows that this treatment should be given only to patients whose growth is causing serious clinical symptoms. There appears to be no point in combining oestrogen therapy with orchidectomy. Adrenalectomy offers no clinical improvement, and hypophysectomy, though practised in some centres, is not generally recommended by this research group.

Perhaps one of the most heartening reports was that from the radiotherapists, who were able to show that in certain hands radiotherapy can produce survival rates at 5 and 10 years comparable with other methods of treatment. ${ }^{8}$ In very advanced cases some benefit may be derived from chemotherapy, particularly with aniline mustard. It was suggested that those tumours respond best which produce $\beta$ glucuronidase, and this may form the basis of a predictive test. This agent is known to circulate in the body as a glucuronide, and it is assumed its activation will occur preferentially in tissue with a high $\beta$-glucuronidase activity.

1 Registrar General's Statistical Review of England and Wales for the Year 1970, Part 1, Tables, Medical, London, H.M.S.O. 1972.

2 Dhom, G., and Hohbach, M., Current Problems in the Epidemiology of Cancer and Lymphomas, p. 139. Berlin, Springer-Verlag, 1972.

Farnsworth, W. E., and Brown, J. R., fournal of the American Medical Association, 1963, 183, 436.

Association, 1963, 183, 436.
Wynder, E. L., Mabuchi, K., and Whitmore, W. F., Cancer, 1971, 28, 344.

s Ashley, D. J. B., Fournal of Pathology and Bacteriology, 1965, 90, 217.

- Belt, E., and Schroeder, F. H., Fournal of Urology, 1972, 107, 91.

7 Fournal of Urology, 1967, 98, 516. Grout, D. C., Grayhack, J. T., Moss, W., and Holland, J. M., Fournal of
Urology, 1971, 105, 411.

\section{Safety in Flying}

The recent survey by Flight International 1 of world airline safety has certainly ruffled the feathers of many concerned in civil flying. Which countries have the safest airlines? To answer this question J. M. Ramsden examined the ten-year records of 15 major air transport nations. But his analysis has since been strongly criticized by the Civil Aviation Authority, which contends that the overall results of a ten-year period do not bring out the improvement which has occurred or the high level of safety which can now be claimed by United Kingdom carriers.

The overall record of world airline safety is impressive. It has been calculated that in a group of a 100 European passengers each involved in 5,000 miles travel by car a year, one would be killed after a lapse of 133 years. If they travelled by air the lapse would be 370 years. Nowadays a passenger would have to complete about half a million flights before he could expect to be involved in a fatal air crash. The data provided by Ramsden for the incidence of fatal accidents showed that Unired Kingdom carriers are sixth in the world league for the 10 years from 1963. The Netherlands lead with no fatal crashes, and over the same period Australia had less than one fatal crash per million flights while Scandinavia and the United States each had fewer than two fatal crashes per million flights. Germany and the United
Kingdom had $2 \cdot 2$ and $3 \cdot 6$, respectively, and the remaining four of the top ten were Canada (4.0), Japan (4.5), Italy (4.7), and Belgium (6.8).

Other measures of air safety are less favourable to the United Kingdom carriers, but Ramsden has attempted to avoid many of the pitfalls in this type of analysis by providing severa! indices. On the one hand, it is reasonable to accept his point of view that the most valid measure is the incidence of fatal accidents related to the number of flights (after all the passenger wants to know the chances of making his destination safely); on the other hand, an important criticism may be levelled against the analysis: essentially it provides a measure of how safe world airlines were during the last 10 years rather than an indication of which ones are the safest now. Thus a very different picture may emerge if one breaks down the results into successive five-year periods. Certainly, in the case of the United Kingdom carriers there has been a sustained improvement. For the five year periods each beginning 1964, 1965, 1966, 1967, and 1968 the total mumber of fatal crashes were $13,12,10,9$, and 6 , respectively; this would suggest that the United Kingdom carriers are better placed in the world air safety stakes than an overall analysis of the past ten years has implied.

About $15 \%$ of the accidents involved technical problems, such as engine or structural failures, but over $40 \%$ occurred during the descent of the aircraft or its approach to an airfield. These latter accidents, which included many collisions with high ground in the vicinity of the airport, suggest deficiencies of the interplay between the flight deck and air traffic control, or inadequate navigational aids. It is important that the international authorities responsible for air safety should ensure that standards are raised where it is evident that deficiencies still persist.

Air safety is a complex problem, and great care should be exercised in the interpretation of past accident figures. It is much more important to derive trends than to dwell on past performance and it is in this direction that more sophisticated analyses may reveal important information.

1Ramsden, J. M., Flight International, 1973, 103, 737.

\section{Aids to Diagnosis in Closed Abdominal Trauma}

Blunt injuries to the abdomen may occur in industrial and home accidents, or may follow kicks and blows, and are especially common after road accidents. They present urgent problems in both diagnosis and management.

In most series the order of frequency with which the viscera are damaged is: kidney, spleen, and liver, followed less commonly by pancreas, intestine, and bladder. Several abdominal organs may be injured, as may other parts of the body. R. D. Williams and A. A. Yurko' reported a consecutive series of 278 patients with closed abdominal injury from Columbus, Ohio; $68 \%$ resulted from road accidents. Two or more abdominal organs were damaged in 84 of these patients; one-third had associated injuries to the head, another third had trauma to the chest, and a quarter had injuries to the limbs.

Clinical diagnosis is all-important, and the surgeon must look out for pain referred to the shoulder tip and for delayed 
rupture of the spleen and, less commonly, the liver. Bruising of the anterior abdominal wall is surprisingly uncommon in association with major intra-abdominal damage, probably because many such cases follow trauma to a relaxed and unguarded abdominal wall, so that the brunt of the injury falls upon the abdominal contents rather than the wall itself. Rupture of a solid organ is suggested by the signs of blood loss together with abdominal guarding and tenderness, with dullness in one or both flanks. A rigid, silent abdomen, without evidence of haemorrhage, is more in favour of rupture of a hollow viscus. Loin tenderness and bruising, together with haematuria, indicate renal damage.

Diagnosis is testing enough in uncomplicated cases, but when the patient has other injuries, and in particular when he is unconscious from a head injury, the problem becomes still more puzzling. Naturally the surgeon looks to ancillary aids. Plain $x$-rays of the abdomen are of limited value, though identification of free gas naturally confirms rupture of a hollow viscus. An emergency intravenous pyelogram is valuable when renal injury is suspected.

Diagnostic paracentesis of the abdominal cavity has been popular for many years in the U.S.A. in cases both of abdominal trauma and of acute abdominal emergency ${ }^{2}$ but has been much less practised in Great Britain. However, W. N. W. Baker and his colleagues ${ }^{3}$ reported a series of 101 acute abdominal emergencies seen at the Central Middlesex Hospital. Paracentesis was positive in about $80 \%$ of their cases of intraperitoneal haemorrhage and perforation, though less than $10 \%$ of localized inflammatory disease gave a positive finding. In cases of blunt abdominal trauma many reports from the United States of tapping two or four quadrants of the peritoneal cavity have shown that, where blood is obtained, $80 \%$ or more of the patients are found to have intra-abdominal injury at laparotomy. But unfortunately there is a high percentage of false negative results.

In an attempt to refine this diagnostic aid the technique of peritoneal lavage was introduced by H. D. Root and his colleagues in 1965.4 E. R. Thal and G. T. Shires 5 now report their experience of 267 patients undergoing peritoneal lavage after abdominal trauma in Dallas, Texas. The technique used was to insert a peritoneal dialysis catheter via a trocar in the lower midline between the umbilicus and the pubis. The catheter was aspirated, and if non-clotting blood returned freely the diagnosis of haemoperitoneum was confirmed and the patient was taken to the operating theatre. If no aspirate was obtained, a litre of Ringer's solution was infused for 5-10 minutes and then siphoned out of the peritoneal cavity. The fluid was examined for blood, amylase, bile, and bacteria. The procedure was not carried out if the diagnosis was obvious clinically, but if a diagnosis could not be made a two-quadrant needle paracentesis was performed. Lavage was carried out only if this procedure in turn was negative. Lavage was also performed when the diagnosis was complicated by a head injury or an altered state of consciousness produced by alcohol, shock, or drugs. Peritoneal lavage was contraindicated in patients who had undergone multiple abdominal operations and in whom the presence of adhesions increased the risk of penetrating the gut. Pregnancy, gross abdominal distension, and gunshot or stab wounds were further contraindications. The criteria for positive results on lavage were considered to be the presence of gross non-clotted blood or the presence of more than 100,000 red cells or 500 white cells per cubic millimetre, a raised amylase level, or the presence of bile or bacteria. Any of these factors was considered to be an indication for laparotomy.

Many patients were spared exploratory laparotomy on the basis of negative lavage results, and only two patients subsequently needed surgery who were admitted to hospital and initially observed. These authors reported 173 patients $(64.8 \%)$ as having negative results from lavage. Among them were nine false negative results $(3 \cdot 1 \%)$. There were also ten false positive results $(3.5 \%)$. But the procedure appears to be a valuable aid whether its results are negative or positive. However, it is not free from complications, and indeed these occurred in 13 patient $(4.5 \%)$. They included infusion of the lavage fluid into the abdominal wall, penetration of the bladder or large small bowel, and laceration of a mesenteric vessel and retroperitoneal haemorrhage. Moreover, lavage is very inaccurate in the diagnosis of retroperitoneal injuries, and most pancreatic trauma was not detected by this technique. An increase of amylase more generally indicates laceration of the bowel than pancreatic trauma.

It should be emphasized that these authors suggest peritoneal lavage only as an aid when the diagnosis is in doubt. Laparotomy should not be delayed when visceral rupture or intraperitoneal bleeding is clinically obvious.

1 Williams, R. D., and Yurko, A. A., American Fournal of Surgery, $1966,111,477$

2 Newhof. H., and Cohen, I., Annals of Surgery, 1926, 83, 454.

3 Baker. W. N. W. Mackie. D. B., and Newcombe, J. F., British Medical fournal, 1967, 3, 146

Root, H. D. Hauser, C .W., McKinley, C. R., LaFave, J. W., and Mendiola, R. P., Surgery, 1965, 57, 633.

5 Thal. E. R., and Shires, G. T., American fournal of Surgery, 1973, 125, 64 .

\section{Syndrome of Gilles de la Tourette}

The pages of the history of medicine contain many personalities who have given their names to syndromes or diseases, and neurology has many examples. Few more colourful names will be found than that of G. Gilles de la Tourette, ${ }^{1}$ who in 1885 described nine patients with persistent multiple tics beginning in childhood, five of whom had verbal tics consisting of repeated expostulations of obscenities and swear-words. To this antisocial behaviour is given the term coprolalia. Other features of the syndrome which have been recognized include the tendency of the patient to repeat words or phrases spoken to him (echolalia), and to show compulsive imitation of movements or gestures (echokinesis or echopraxia). The compulsive, multiple, repetitive, complex movements (tics), particularly of the face and arms, gave rise to the term "maladie des tics convulsifs" or "impulsifs".2

The vocal tics show all varieties from grunts or barks to fully formed and explicit obscenities. Coprolalia is common in chronic paranoid schizophrenia and, some would say, too common as a social "grace" in a proportion of the normal male population. Tics similarly are not uncommon, and there is a suggestion that the syndrome of Gilles de la Tourette is simply the extreme end of the spectrum of tics in gentral. ${ }^{3}$ However, the fully fledged picture of the syndrome is striking and relatively rare.

The condition begins in childhood, in $85 \%$ before the age of 11 years. Males are affected three times as commonly as 